\title{
Occupational risk factors among Iranian farmworkers: a review of the available evidence
}

\author{
Mahin Ghafari', Zahra Cheraghi' ${ }^{2}$ Amin Doosti-Irani ${ }^{2}$ \\ 'Department of Public Health, School of Health, Shahrekord University of Medical Sciences, Shahrekord, Iran; '2Department of Epidemiology, \\ School of Public Health, Hamadan University of Medical Sciences, Hamadan, Iran
}

\begin{abstract}
Farming is one of the most important components of most economies. No comprehensive picture exists of the health status of Iranian farmers and the work-related hazards that affect them. We aimed to determine the gaps in the current knowledge regarding the occupational health of Iranian farmworkers. Electronic databases including Medline, Web of Science, Scopus, and Embase, as well as national databases including the Scientific Information Database, MagIran, and Barakat Knowledge System, were searched for articles published through March 2017. All epidemiologic studies regarding the occupational health of farmworkers in Iran were reviewed, regardless of their design, language, time of publication, and location. Of the 86 retrieved articles, 39 studies were ultimately analyzed. Most studies were conducted in Fars, Kerman, and Mazandaran provinces. According to the results of this review, chemical, physical, and biological hazards, along with work-related injuries, may be the main factors threatening the health of farmworkers. The unsafe use of pesticides was related to male infertility, eye and digestive complications, pesticide poisoning, pesticide absorption, hematological changes, non-Hodgkin lymphoma, and multiple myeloma. Chemical hazards (e.g., the unsafe use of pesticides), physical hazards, injuries, and biological hazards (e.g., work-related infectious diseases) threaten the health of Iranian farmworkers. Moreover, farmworkers lack adequate knowledge about the occupational hazards they face and the relevant risk factors.
\end{abstract}

KEY WORDS: Occupational health, Risk factors, Farmworkers, Iran

\section{INTRODUCTION}

Farming is one of the most important components of the economy in most countries. It exerts major effects on both public health and food safety. The agricultural workforce, consisting of over 1.1 billion individuals, is the largest workforce in the world. Moreover, the health of farmworkers has an important role in food provision [1]. Farming is known as a high-risk job in both

\section{Correspondence: Amin Doosti-Irani}

Department of Epidemiology, School of Public Health, Hamadan University of Medical Sciences, Shahid Fahmideh Ave., Hamadan 65157835129, Iran

E-mail:a_doostiirani@yahoo.com

Received: Jun 1, 2017 / Accepted: Jul 2, 2017 / Published: Jul 2, 2017

This article is available from: http://e-epih.org/

(C) This is an open-access article distributed under the terms of the Creative Commons Attribution License (http://creativecommons.org/licenses/by/4.0/), which permits unrestricted use, distribution, and reproduction in any medium, provided the original work is properly cited.

(C) 2017, Korean Society of Epidemiology developed and developing countries [1,2]. In addition to exposure to physical, chemical, and biological risk factors, work-related injuries and accidents can also threaten the health of farmworkers [3-5].

Agriculture plays an important economic role in the lives of people in many countries, including Iran [6]. In 2015, more than $18.0 \%$ of employees (approximately 4 million people) in Iran worked in the farming sector [7]. According to previous studies, occupational hazards such as musculoskeletal disorders [8] and injuries [9], pesticide poisoning, skin cancer, and infectious diseases threaten the health of Iranian farmworkers [10-12]. Unfortunately, there is no comprehensive occupational health monitoring system for farming-related diseases and injuries in Iran. Based on the available health indices, in 2010 , only $32.0 \%$ of Iranian farmworkers were registered with the health system. Of these, $18.7 \%$ were covered by health care services and regular screening tests [13].

However, despite the magnitude of agricultural areas and the agricultural workforce in Iran, limited epidemiologic research has 
evaluated the health status and potential occupational hazards among farmworkers in different regions of the country. We aimed to review all the published studies in the field of the occupational risk factors for farmers and to determine the gaps in the current knowledge regarding the occupational health of Iranian farmworkers.

\section{MATERIALS AND METHODS}

\section{Searching}

Electronic databases, including Medline, Web of Science, Scopus, and Embase, were searched for studies published until March 2017. The search keywords were occupational injuries, occupational exposure, occupational diseases, occupational health, biohazard release, chemical hazard release, physical hazard, farmer, farmworkers, agricultural workers, and Iran. We also searched national databases, such as the Scientific Information Database, MagIran, and Barakat Knowledge System, for articles published until the same date. The reference lists of the selected studies were also evaluated.

All epidemiologic studies about the occupational health of Iranian farmworkers were included, regardless of their design, language, location, and time of publication. Case reports and letters to the editor were excluded.

\section{Study selection and data extraction}

Two authors (Z Cheraghi and A Doosti-Irani) assessed the titles and abstracts of the retrieved articles. The full texts of the selected studies were then reviewed according to the eligibility criteria. The first author's name, study design (cross-sectional, case-control, or cohort) and aims, sample size, year of publication, language, location of the study, the participants' gender and mean age, type of occupational hazard, type of outcome or disease, and the main findings of the selected studies were extracted.

\section{Quality assessment}

Two authors (Z Cheraghi and A Doosti-Irani) were responsible for quality assessment. For cohort and case-control studies, the Newcastle-Ottawa Quality Assessment Scale was used for quality determination [14]. For cross-sectional studies, we used the modified version of the Newcastle-Ottawa scale. The maximum score on this scale is 8 . We categorized the quality of studies based on this score as follows: scores of 6 and above indicated high quality, 5-6 moderate quality, and 4 and lower low quality.

Microsoft Excel (Microsoft Corp., Redmond, WA, USA) was used for the extraction and management of data. Descriptive data analysis was performed in order to obtain the frequency and distribution of conducted studies according to the type of occupational hazard studied, the type of outcome or occupational disease, and the location of the study. The ArcMap version 9.3 (Esri, Redlands, CA, USA) was used to generate a map of Iran based on published studies in the field of occupational health among farmworkers.

\section{RESULTS}

A total of 86 articles, including 7 from Web of Science, 2 from PubMed, 46 from Scopus, and 31 from national databases, were selected. After removing the duplicates $(n=19)$, the titles and abstracts of the remaining 67 articles were evaluated. In the next step, the full texts of 45 articles were checked according to the eligibility criteria, and 39 studies $[10,12,15-50]$ were finally included in this review.

The distribution of the selected studies across provinces is shown in Figure 1. No studies assessed the occupational health of

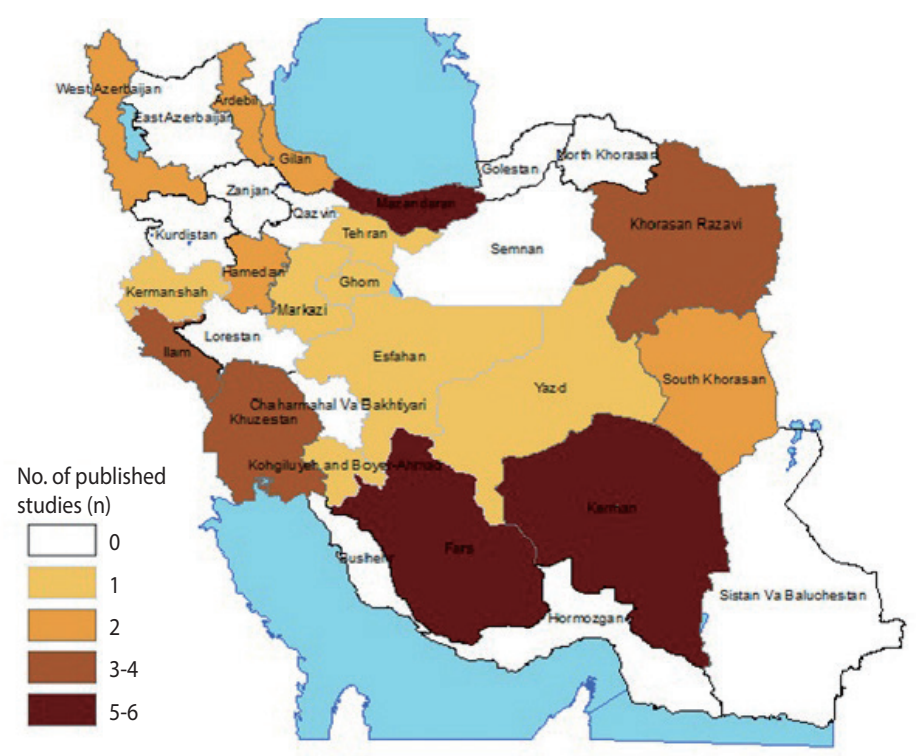

Figure 1. The distribution of the published studies regarding the occupational health of Iranian farmworkers. 


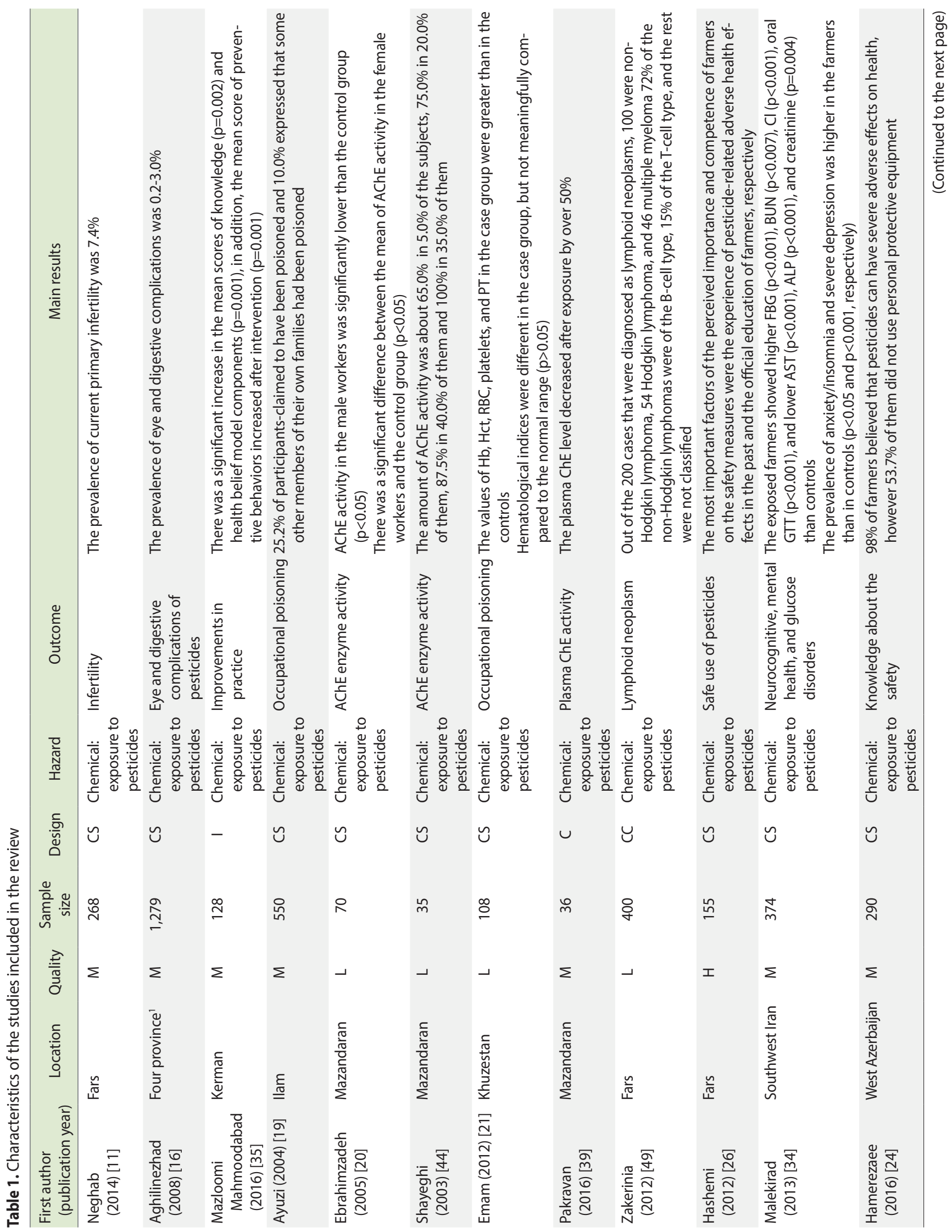




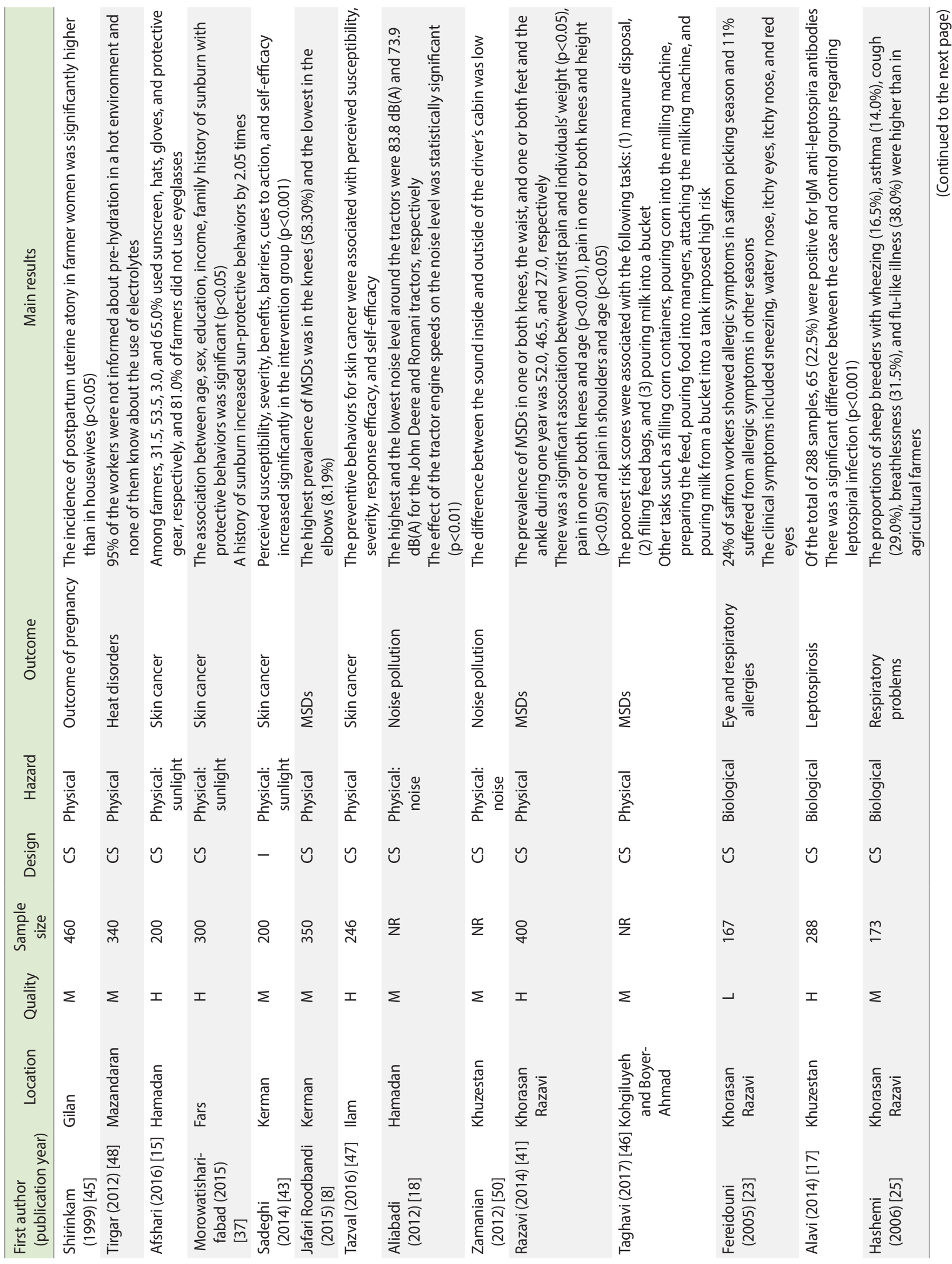




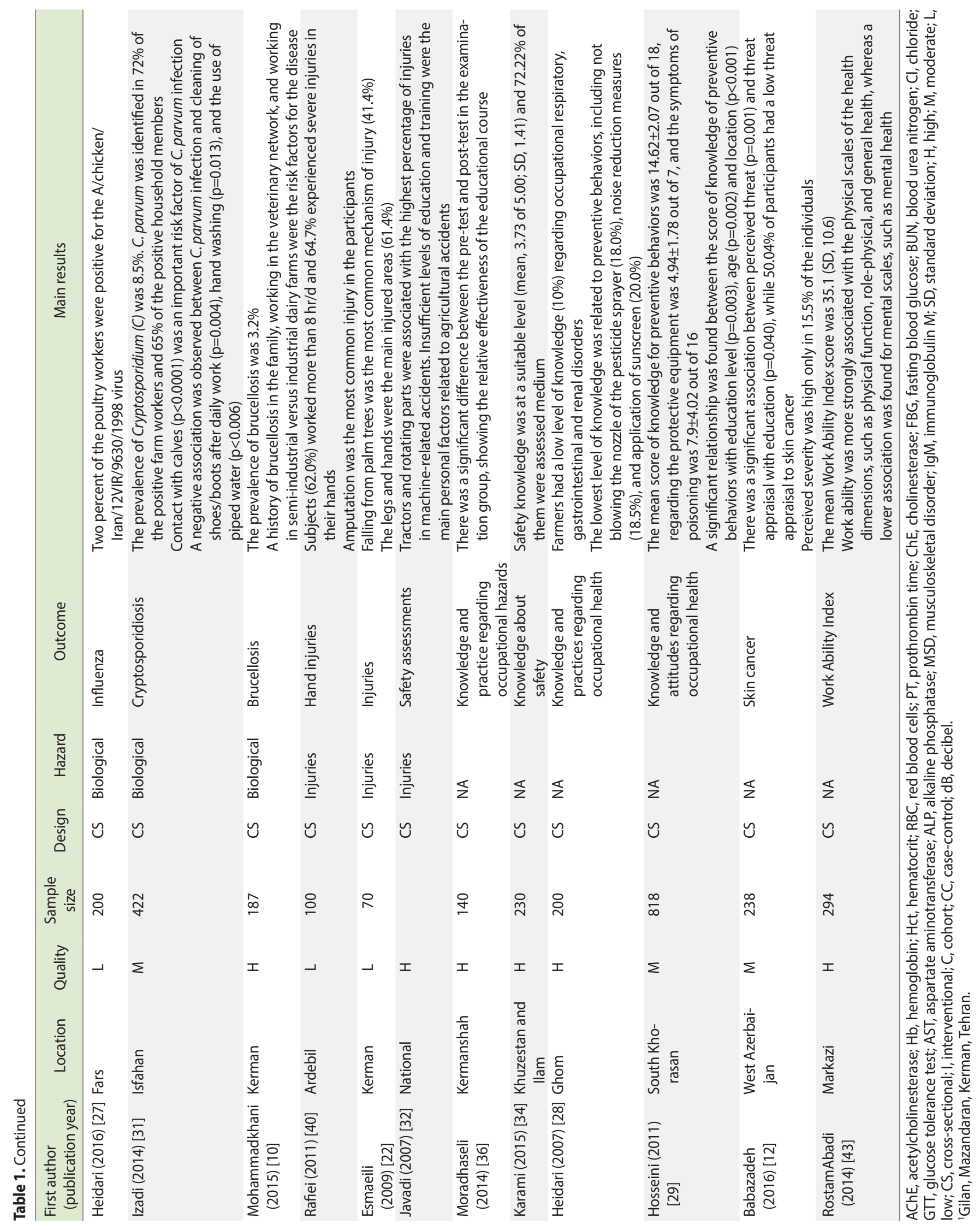


farmers in east Azerbaijan, Zanjan, Kurdistan, Ghazvin, Golestan, and north Khorasan provinces. Most studies were conducted in Fars, Kerman, and Mazandaran provinces. The characteristics of the included studies are summarized in Table 1.

\section{Studies regarding chemical hazards}

Twelve studies assessed chemical hazards, including pesticide exposure, among farmworkers. Neghab et al. [11] examined the relationship between the prevalence of infertility and pesticide exposure among farmworkers. They found infertility to be more prevalent among farmworkers than in the general population $(\mathrm{p}<0.05)$ and suggested pesticide exposure as a possible cause.

Aghilinezhad et al. [16] assessed the effects of pesticides on the health of farmworkers. Based on their findings, $68 \%$ of the farmworkers did not use personal protective equipment during the administration of pesticides. In addition, eye and digestive complications of pesticide exposure were quite common among the studied farmworkers.

Mazloomi Mahmoodabad et al. [35] designed an interventional study to clarify the effectiveness of the health belief model (HBM) on the preventive behaviors of farmworkers regarding exposure to pesticides. They concluded that HBM-based education was effective in promoting preventive behaviors among farmworkers $(\mathrm{p}<0.001)$.

According to Ayuzi \& Poornajaf [19], 25.2\% of the studied farmworkers reported occupational poisoning with pesticides. Ebrahimzadeh et al. [20] and Shayeghi \& Shayeghi [44] assessed the absorption rate of pesticides among farmworkers in rice farms. They reported that the absorption of pesticides was higher among the farmworkers than in the general population.

Emam et al. [21] evaluated the effects of pesticides on hematological parameters among farmworkers. They found that hematological parameters such as hemoglobin $(p=0.002)$, hematocrit $(\mathrm{p}=0.001)$, and prothrombin time $(\mathrm{p}=0.001)$, were higher in farmworkers than in workers with other occupations. Pakravan et al. [39] measured plasma cholinesterase activity before and after exposure to organophosphate pesticides in farmworkers. Based on their findings, pesticide exposure decreased plasma cholinesterase levels by $50 \%$.

Zakerinia et al. [49] found an association between pesticide exposure and both non-Hodgkin lymphoma (odds ratio [OR], 3.9; 95\% confidence interval [CI], 2.2 to 6.8 ) and multiple myeloma (OR, 2.48; 95\% CI, 1.16 to 5.2 ).

Hashemi et al. [26] and Hamerezaee et al. [24] studied the factors affecting the safe use of pesticides and knowledge regarding safety in the administration of pesticides, respectively. They both highlighted the necessity of training courses on the safe use of pesticides for farmworkers. In a cross-sectional study, Malekirad et al. [34] showed exposure to organophosphorus pesticides to be associated with neuropsychological disorders $(\mathrm{p}<0.001)$.

\section{Studies regarding physical hazards}

Eleven studies focused on physical hazards among farmwork- ers. Shirinkam \& Fani [45] compared the outcomes of pregnancy among farmers and non-farmers. They reported a higher incidence of preterm delivery and low birth weight among female farmworkers, but the difference was not statistically significant.

Four studies assessed the role of sun protection in skin cancer prevention $[15,37,43,47]$. They all underscored the significance of training and educational interventions on sun-protecting behaviors in skin cancer prevention among farmworkers.

Tirgar et al. [48] measured the risk of heat disorders among farmworkers. They indicated that farmworkers were prone to a variety of heat exhaustion disorders. Moreover, farmworkers lacked adequate knowledge regarding the risk of heat exhaustion on their health.

Three cross-sectional studies $[8,41,46]$ determined the prevalence of musculoskeletal disorders and related risk factors among farmworkers. They calculated the prevalence of musculoskeletal disorders in the elbows, knees, back, and legs to be 19.8, 52.0-58.3, 46.5 , and $27.0 \%$, respectively.

Two studies $[18,50]$ focused on the noise pollution of agricultural machinery and identified noise pollution as an occupational hazard among the drivers of agricultural machinery. They thus recommended the use of hearing protective devices, improvements in the cabin of agricultural machinery, educational interventions, and hearing exams to be essential for the prevention of hearing disorders among farmworkers.

\section{Studies regarding injuries}

Three studies focused on occupational injuries among farmworkers. According to Javadi \& Rostami [32], three groups of factors (personal, mechanical, and environmental factors) affected the incidence of injuries. They reported that $53 \%$ of injuries were related to personal factors and that $40 \%$ were related to a combination of both mechanical and personal factors. Esmaeili et al. [22] found falls from trees (41.4\%) to be the most common cause of work-related injuries among farmworkers. Moreover, the feet (35.7\%) and hands (25.7\%) were the most frequently damaged organs. Rafiei et al. [40] identified hand amputations as the most common injury (54\%) among farmworkers.

\section{Studies regarding biological hazards}

Six studies were related to biological hazards and work-related infectious diseases among farmworkers. Two studies assessed eye and respiratory allergies in saffron farmers [23] and respiratory problems among sheep farmers [25]. Studies on work-related infectious diseases have indicated that leptospirosis was common in rice farmers [17], avian influenza H9N2 was prevalent among poultry workers [27], and cryptosporidiosis [31] and brucellosis [10] were common among farmworkers in general.

Studies on the knowledge, attitude, and practices of farmers regarding occupational health.

Six studies [12,28-30,33,36] assessed the knowledge of farmworkers regarding their occupational health. They concluded that educational interventions were necessary for health promotion 
and work-related disease prevention among the farmworkers.

\section{DISCUSSION}

Based on the reviewed articles, chemical, physical, and biological hazards, as well as occupational injuries, are the main threats to the health of Iranian farmworkers. However, since most studies were limited to particular provinces (such as Kerman, Fars, and Gilan) and no research in this field was conducted in a number of provinces, the available evidence cannot be interpreted as providing an accurate picture of the health status of the farmworkers throughout the country. However, based on the available health indicators in 2010, only $32.0 \%$ of Iranian farmworkers were registered with the health system and $18.7 \%$ of them were covered by occupational health care services [13].

According to the results of the reviewed studies, the unsafe use of pesticides causes male infertility, eye and digestive complications, pesticide poisoning, pesticide absorption, hematological changes, non-Hodgkin lymphoma, and multiple myeloma. Therefore, despite the abovementioned limitations, the available evidence confirms that the unsafe use of pesticides is a considerable threat to the health of Iranian farmworkers. Based on the results of studies in other countries, exposure to pesticides is associated with other diseases such as prostate cancer [51], Parkinson disease [52], breast cancer, thyroid cancer, and ovarian cancer [53]. Educational interventions about the safe use of pesticides and periodic checkups of farmworkers are hence necessary to prevent pesticide-related diseases among Iranian farmworkers.

Physical hazards such as heat, sunlight, and improper physical work also threaten the health of Iranian farmworkers. Farmworkers are at risk of skin cancer because of exposure to ultraviolet radiation [54]. Long working hours, especially in the summer, increase the risk of skin cancer among Iranian farmworkers. Moreover, Iranian farmworkers lack adequate knowledge regarding sun-protective behaviors [12,15]. Thus, educational interventions about skin cancer prevention are also essential for Iranian farmworkers. In addition, due to the inadequacy of the available evidence regarding skin cancer among Iranian farmworkers, further studies from all agricultural areas of Iran are required before preventive interventions are planned.

Based on the evaluated studies, musculoskeletal disorders are also prevalent in Iranian farmworkers. These disorders are generally common among all farmworkers [55,56]. Nevertheless, more studies are warranted to identify the prevalence and related risk factors of these disorders among Iranian farmworkers. Ergonomic and educational interventions are also necessary to encourage farmworkers to adopt a correct posture during physical work.

Occupational injuries are prevalent among Iranian farmworkers. Injuries to the hands, feet, and eyes can affect the health, quality of life, and economic status of farmworkers. Some injuries may even lead to death. Injuries thus impose a considerable burden on the families of farmworkers, the agricultural sector, and the community. Since only 3 studies assessed work-related injuries among
Iranian farmworkers, further studies are needed in this field.

Work-related infectious diseases, such as brucellosis, avian influenza, leptospirosis, Q fever, and cryptosporidiosis, are prevalent among farmworkers $[10,27,57,58]$. However, due to the limited number of studies $(n=4)$ on infectious diseases among Iranian farmworkers, the available evidence cannot be interpreted as reflecting the actual status of these diseases, and further epidemiologic studies in this field are warranted.

This review had the limitation that most of the included studies were cross-sectional and therefore did not provide sufficient evidence regarding the risk factors of work-related diseases. Moreover, while the quality of some studies was low, we included all available studies, regardless of quality, due to the limited number of available studies.

Based on the results of this review, it is recommended that Iranian health policymakers and occupational health researchers develop a national registry system to register occupational diseases and injuries among farmworkers, pay more attention to the health status of farmworkers at the national and subnational levels, perform research on the occupational health of farmworkers, determine research priorities based on epidemiologic findings, and clarify the health status of farmworkers by designing a national cohort study.

\section{CONCLUSION}

Although insufficient evidence exists regarding the health status of Iranian farmworkers, the available evidence showed that work-related diseases are prevalent in farmers. Chemical hazards (e.g., the unsafe use of pesticides), physical hazards, injuries, and biological hazards (e.g., work-related infectious diseases) threaten the health of Iranian farmworkers. Moreover, the knowledge of farmworkers about work-related hazards and risk factors is not sufficient.

\section{CONFLICT OF INTEREST}

The authors have no conflicts of interest to declare for this study.

\section{ORCID}

Mahin Ghafari: https://orcid.org/0000-0002-9441-7557; Zahra Cheraghi: https://orcid.org/0000-0001-9041-559X; Amin DoostiIrani: https://orcid.org/0000-0003-0623-7503

\section{REFERENCES}

1. Hurst P, Kirby P. Health, safety and environment: a series of trade union education manuals for agricultural workers; 2004 [cited 2017 Jul 13]. Available from: http://www.ilo.org/wcmsp5/groups/ public/---ed_dialogue/---actrav/documents/publication/wcms_ 111413.pdf.

2. Stoleski S, Minov J, Mijakoski D. Bronchial hyperresponsiveness 
in farmers: severity and work- relatedness. Maced J Med Sci 2014;7:536-543.

3. Geng Q, Stuthridge RW, Field WE. Hazards for farmers with disabilities: working in cold environments. J Agromedicine 2013;18: 140-150.

4. Cha ES, Jeong M, Lee WJ. Agricultural pesticide usage and prioritization in South Korea. J Agromedicine 2014;19:281-93.

5. Guthrie R, Westaway J, Goldacre L. Workers compensation and occupational health and safety in the Australian agricultural industry. Aust J Rural Health 2009;17:77-85.

6. McLachlan K. The neglected garden: the politics and ecology of agriculture in Iran. London: Tauris; 1988, p. 1-7.

7. Statistical Center of Iran. Detailed results of general agricultural census of the whole country [cited 2017 Jul 28]. Available from: https://www.amar.org.ir/Portals/0/keshavarzi93/results/agri9399.pdf (Persian).

8. Jafari Roodbandi A, Dneshvar S, Sadeghi M, Barsam T, Rahimi Moghadam S, Feyzi V. The prevalence of musculoskeletal disorders and its contributing factors in farmers of Zarand in 20102011. J Occup Hyg Eng 2015;2:23-31 (Persian).

9. Sadeghifard V. Causes and types of amputation from occupational trauma in patients referred to Fatemi hospital in Ardabil city, 2011. J Health 2014;5:235-239 (Persian).

10. Mohammadkhani M, Sharifi H, Rashidi H, Nabipour AR, Jahanshahi M. Seroepidemiology of brucellosis in industrial and semiindustrial dairy personnel and veterinary network staff in Kerman, 2012. Iran J Epidemiol 2015;10:54-61 (Persian).

11. Neghab M, Momenbella-Fard M, Naziaghdam R, Salahshour N, Kazemi M, Alipour H. The effects of exposure to pesticides on the fecundity status of farm workers resident in a rural region of Fars province, southern Iran. Asian Pac J Trop Biomed 2014;4: 324-328.

12. Babazadeh T, Tazval J, Moradi-Joo M, Moradi F, Mirzaeian K. Threat appraisal of skin cancer in farmers of Chaldoran county, 2014-2015. Community Health J 2016;10:40-51 (Persian).

13. Deputy of Public Health. Public health profile indicators in the Islamic Republic of Iran 2006-2010 [2017 May 2]. Available from: http://markazsalamat.behdasht.gov.ir/ (Persian).

14. Stang A. Critical evaluation of the Newcastle-Ottawa scale for the assessment of the quality of nonrandomized studies in metaanalyses. Eur J Epidemiol 2010;25:603-605.

15. Afshari M, Afshari M, Bahrami M, Kangavari M. Study the factors preventing skin cancer in farmers Tuyserkan city based on protection motivation theory. Iran Occup Health 2016;13:80-90 (Persian).

16. Aghilinezhad MA, Mohammadi S, Farshad AA. Effect of pesticides on farmers' health. Res Med 2008;31:327-331 (Persian).

17. Alavi SM, Khoshkho MM. Seroprevalence study of leptospirosis among rice farmers in khuzestan province, south west Iran, 2012. Jundishapur J Microbiol 2014;7:e11536.

18. Aliabadi M, Chavoshi E, Hajalizadeh H. Determination of noise pollution propagated from agricultural tractors and its driver's noise exposure level. J Health Saf Work 2012;2:43-52 (Persian).
19. Ayuzi AA, Poornajaf A. Epidemiology of occupational poisoning with pesticides among farmers in Ilam province. J Ilam Univ Med Sci 2004;12(3):40-52 (Persian).

20. Ebrahimzadeh MA, Shokrzadeh M, Bioukabadi M. Effect of organophosphorous pesticides on acetyl cholinesterase activity in agricultural workers. J Shahrekord Univ Med Sci 2005;7:1-7 (Persian).

21. Emam SJ, Salehcheh M, Haghighizadeh MH, Jazayeri SM. Occupational exposure to pesticides among farmers. Pak J Med Sci 2012;28:120-123.

22. Esmaeili A, Vazirinejad R, Shahrokhi F. An annual survey of work: induced accidents in injured farmers referring to health centers in Bam. Occup Med J 2009;1:42-46 (Persian).

23. Fereidouni M, Sankian M, Varasteh AR. The prevalence of saffron pollen allergy in saffron workers of Khorasan (Iran) in 2002. J Kerman Univ Med Sci 2005;12:7-13 (Persian).

24. Hamerezaee M, Fathi A, Rahimi N, Heidarnejad N, Barzegar L, Hamdia S. The assessment of knowledge, attitude and practices of farmers and gardeners to the safety issues when using pesticides in the farms of west Azerbaijan province. Hozan 2016;2:30-37 (Persian).

25. Hashemi N, Mirsadraee M, Shakeri MT, Varasteh AR. Prevalence of work-related respiratory symptoms in Iranian farmers. Can Respir J 2006;13:198-202.

26. Hashemi SM, Hosseini SM, MK. Farmers' perceptions of safe use of pesticides: determinants and training needs. Int Arch Occup Environ Health 2012;85:57-66.

27. Heidari A, Mancin M, Nili H, Pourghanbari GH, Lankarani KB, Leardini S, et al. Serological evidence of H9N2 avian influenza virus exposure among poultry workers from Fars province of Iran. Virol J 2016;13:16.

28. Heidari A, Razavi Asl S. Agricultural occupational health knowledge and practice of farmers in 2007 in Qom province. Qom Univ Med Sci J 2007;1:51-58 (Persian).

29. Hosseini MH, Ramazani A, Hanafie Bojd M, Hamidi H, Samimi K, Mohsenzadeh MA, et al. Farmers' knowledge of occupational poisonings in south Khorasan, 2009. J Birjand Univ Med Sci 2011;18:47-54 (Persian).

30. Hosseini MH, Ramazani AA, Tavasolian H, Mohsenzadeh MA, Maleki S, Samimi K. Survey of knowledge and attitude of farmers of southern Khorasan province regarding agriculture related OHS issues in 2008. Iran Occup Health 2011;8:24-29 (Persian).

31. Izadi M, Jonaidi-Jafari N, Saburi A, Eyni H, Rezaiemanesh MR, Ranjbar R. Cryptosporidiosis in Iranian farm workers and their household members: a hypothesis about possible zoonotic transmission. J Trop Med 2014;2014:405875.

32. Javadi A, Rostami MA. Safety assessments of agricultural machinery in Iran. J Agric Saf Health 2007;13:275-284.

33. Karami G, Bijani M, Salamat E. Agricultural experts' safety knowledge toward work with agricultural machinery in south west of Iran. J Occup Hyg Eng 2015;1:30-39 (Persian).

34. Malekirad AA, Faghih M, Mirabdollahi M, Kiani M, Fathi A, Abdollahi M. Neurocognitive, mental health, and glucose disor- 
ders in farmers exposed to organophosphorus pesticides. Arh Hig Rada Toksikol 2013;64:1-8.

35. Mazloomi Mahmoodabad SS, Rezaeian M, Hosseinzadeh N, Fallahzadeh H, Barkhordari A. Effectiveness of education based on health belief model (HBM) on preventive behaviors of pesticide exposure in agricultural worker. Tolooebehdasht 2016;14:247260 (Persian).

36. Moradhaseli S, Mirakzadeh A, Rostami F. Analysis the effectiveness of safety and agricultural professional healthy courses which carried out for farmers. Occup Med 2014;6:50-59 (Persian).

37. Morowatisharifabad MA, Bonyadi F, Ebrahimzadeh Ardakani M, Falahzadeh H, Malekzadeh E. Study of sun protective behaviors for skin cancer prevention and its barriers among Kazeroon farmers. Tolooebehdasht 2015;13:68-82 (Persian).

38. Neghab M, Momenbella-Fard M, Naziaghdam R, Salahshour N, Kazemi M, Alipour H. The effects of exposure to pesticides on the fecundity status of farm workers resident in a rural region of Fars province, southern Iran. Asian Pac J Trop Bio 2014;4:324328.

39. Pakravan N, Shokrzadeh M, Bari MA, Shadboorestan A. Measurement of cholinesterase enzyme activity before and after exposure to organophosphate pesticides in farmers of a suburb region of Mazandaran, a northern province of Iran. Hum Exp Toxicol 2016;35:297-301.

40. Rafiei M, Norouzi V, Sadeghifard V, Hoseinnejad S, Amani F. Study of causes of the hand injuries in farmers and industrial workers reffered to emergency department of Fatemi hospital, Ardabil. J Ardabil Univ Med Sci 2011;11:43-51 (Persian).

41. Razavi SM, Bashtani A, Zarghani S, Tabarraie Y. A survey on prevalence of musculoskeletal disorders and associated risk factors among Sabzevarian farmers in 2011. J Sabzevar Univ Med Sci 2014;20:766-772 (Persian).

42. Rostamabadi A, Mazloumi A, Rahimi Foroushani A. Work Ability Index (WAI) and its health-related determinants among Iranian farmers working in small farm enterprises. J Occup Health 2014;56:478-484.

43. Sadeghi R, Khanjani N, Hashemi M, Movagheripour M. Using health belief model to prevent skin cancer among farmers. Iran J Health Educ Health Promot 2014;2:215-222.

44. Shayeghi M, Shayeghi S. Effects of Malathion insecticides on the function of cholinesterase enzyme among the agricultural sprayers. Armaghan Danesh 2003;7:31-36 (Persian).

45. Shirinkam F, Fani L. The assessment of pregnancy outcome in farmer women and bousewiues in Gilan. J Mazandaran Univ Med Sci 1999;9:47-53 (Persian).

46. Taghavi SM, Mokarami H, Ahmadi O, Stallones L, Abbaspour A, Marioryad H. Risk factors for developing work-related musculo- skeletal disorders during dairy farming. Int J Occup Environ Med 2017;8:39-45.

47. Tazval J, Ghafari M, Mohtashami Yeganeh F, Babazadeh T, Rabati R. Efficiency of protection motivation theory on prediction of skin cancer and sunlight preventive behaviors in farmers in Ilam county. J Health 2016;7:656-667 (Persian).

48. Tirgar A, Shirouye A, Hajiahmadi M, Hoseini SR. Determination of susceptibility to heat-related disorders and prevention methods among agriculture workers. J Health Saf Work 2012;1:39-46 (Persian).

49. Zakerinia M, Namdari M, Amirghofran S. The relationship between exposure to pesticides and the occurrence of lymphoid neoplasm. Iran Red Crescent Med J 2012;14:337-344.

50. Zamanian Z, Satiarvand M, Naserpour M, Dehghani M. Evaluation of sound propagation inside the cabin and outside the agriculture machinery of sugarcane industry in both mobile and stationary state. J Health Saf Work 2012;2:1-10 (Persian).

51. Lemarchand C, Tual S, Boulanger M, Levêque-Morlais N, Perrier $\mathrm{S}$, Clin B, et al. Prostate cancer risk among French farmers in the AGRICAN cohort. Scand J Work Environ Health 2016;42:144152.

52. Moisan F, Spinosi J, Delabre L, Gourlet V, Mazurie JL, Bénatru I, et al. Association of Parkinson's disease and its subtypes with agricultural pesticide exposures in men: a case-control study in France. Environ Health Perspect 2015;123:1123-1129.

53. Lerro CC, Koutros S, Andreotti G, Friesen MC, Alavanja MC, Blair A, et al. Organophosphate insecticide use and cancer incidence among spouses of pesticide applicators in the Agricultural Health Study. Occup Environ Med 2015;72:736-744.

54. Gaetano DE, Hodge B, Clark A, Ackerman S, Burdick P, Cook ML. Preventing skin cancer among a farming population: implementing evidence-based interventions. AAOHN J 2009;57:2431.

55. Jo H, Baek S, Park HW, Lee SA, Moon J, Yang JE, et al. Farmers' cohort for agricultural work-related musculoskeletal disorders (farm) study: study design, methods, and baseline characteristics of enrolled subjects. J Epidemiol 2016;26:50-56.

56. Tonelli S, Culp K, Donham KJ. Prevalence of musculoskeletal symptoms and predictors of seeking healthcare among Iowa farmers. J Agric Saf Health 2015;21:229-239.

57. Okoye JO, Eze DC, Krueger WS, Heil GL, White SK, Merrill HR, et al. Evidence for subclinical H5N1 avian influenza infections among Nigerian poultry workers. J Med Virol 2014;86:2070-2075.

58. Monno R, Fumarola L, Trerotoli P, Cavone D, Giannelli G, Rizzo $\mathrm{C}$, et al. Seroprevalence of $\mathrm{Q}$ fever, brucellosis and leptospirosis in farmers and agricultural workers in Bari, southern Italy. Ann Agric Environ Med 2009;16:205-209. 